\title{
Trends in Patient-Perceived Shared Decision Making Among Adults in the United States, 2002-2014
}

\author{
David M. Levine, MD, MPH, $M A^{1,2}$ \\ Bruce E. Landon, MD, MBA, \\ $\mathrm{MSc}^{2,3,4 *}$ \\ Jeffrey A. Linder, $M D, M P H^{5 *}$ \\ *Dr Landon and Dr Linder contributed equally to \\ this manuscript \\ 'Division of General Internal Medicine \\ and Primary Care, Brigham and Women's \\ Hospital, Boston, Massachusetts \\ ${ }^{2}$ Harvard Medical School, Boston, \\ Massachusetts \\ ${ }^{3}$ Department of Health Care Policy, \\ Harvard Medical School, Boston, \\ Massachusetts \\ ${ }^{4}$ Division of General Medicine and Primary \\ Care, Beth Israel Deaconess Medical \\ Center, Boston, Massachusetts
}

${ }^{5}$ Division of General Internal Medicine and Geriatrics, Northwestern University Feinberg School of Medicine, Chicago, Illinois

Conflicts of interest: authors report none.

\section{CORRESPONDING AUTHOR}

David Michael Levine, MD, MA

Division of General Internal Medicine and Primary Care

Brigham and Women's Hospital

1620 Tremont St, 3rd Fl

Boston, MA 02120

dmlevine@partners.org

\begin{abstract}
To ascertain changes in shared decision making (SDM), we analyzed data from the nationally representative Medical Expenditure Panel Survey. We aggregated responses to questions into a 7-point SDM composite score. Between 2002 and 2014, the mean SDM composite score increased from 4.4 to $5.0(P<.01)$, indicating greater patient-perceived SDM. In multivariate modeling, SDM scores were higher for black vs white patients (+0.33 points) and those with a same-race/ ethnicity usual source of care $(+0.24$ points; both $\mathrm{P}<.05)$. Scores were lower for patients with poor-perceived health ( -0.41 points), Asian vs white race/ethnicity $(-0.28$ points), and no insurance $(-0.17$ points; all $\mathrm{P}<.05)$. Improvement efforts should target Americans without a same-race/ethnicity usual source of care and with poor-perceived health.
\end{abstract}

Ann Fam Med 2017;15:552-556. https://doi.org/10.1370/afm.2132.

\section{INTRODUCTION}

$\Omega^{b}$ hared decision making (SDM) occurs when a patient and clinician both participate in medical decision making, jointly weighing medical evidence and patient preferences. The 4 components of SDM are that both the clinician and patient are involved in decision making, share information, build consensus, and agree on treatment. ${ }^{1}$

SDM has benefits, including improved patient knowledge and reduced uncertainty and overuse. ${ }^{2-4}$ Consequently, this form of decision making has been endorsed by professional societies and legislation. ${ }^{5,6}$ Despite considerable efforts to improve SDM, however, scant data exist on how it has changed nationally over time.

\section{METHODS}

We analyzed data from adults aged 18 years and older participating in the 2002 to 2014 Medical Expenditure Panel Survey (MEPS), a nationally representative survey of repeated cross-sections of the noninstitutionalized US civilian population. ${ }^{7}$ Each year, 21,915 to 26,509 participants completed this survey (response rate $=49 \%$ to $65 \%$ ). The MEPS includes an additional mail-back component, the adult self-administered questionnaire, which contains additional items measuring respondents' attitudes about health care (annual response rate range $=91 \%$ to $94 \%$ ).

Participants self-reported having a usual source of care by naming a specific clinician to which "you usually go if you are sick or need advice about your health" and the race/ethnicity of that clinician.

We determined use of SDM as perceived by participants from their responses to 7 questions (annual response rate $=91 \%$ to $94 \%$ ). ${ }^{8,9}$ Three questions were presented only if the participant had a usual source of care; others were presented if the participant had visited a clinic at least once in the past year. We included only respondents who answered all 7 questions: 12,138 in 2002 and 9,049 in 2014.

Six of the questions on the MEPS questionnaire had a never/some- 
times/usually/always response scale: how often did your clinician (1) ask you to help decide; (2) show respect for alternative treatments; (3) listen carefully to you $_{i}$ (4) explain things so they were easy to understand; (5) show respect for you; and (6) spend enough time with you. The final question on the MEPS questionnaire had yes/ no response options and asked did your clinician present all the options to you (for verbatim questions, see Supplemental Appendix 1, available at http://www.annfammed. org/content/15/6/552/suppl/ DC1/). We computed an SDM composite score for each participant, defined as his or her total number of "always" or "yes" responses (for analysis of scores as continuous variables, see Supplemental Appendix 2, available at http:// www.annfammed.org/content/15/6/552/suppl/DC1/). Possible composite scores therefore ranged from 0 to 7 , with higher scores indicating greater SDM.

To assess whether patientreported SDM changed over time, we compared the mean SDM composite between 2002 and 2014 with a $\chi^{2}$ test adjusted for the survey design. ${ }^{10}$ To evaluate independent predictors of SDM, we used multivariate linear regression analysis, adjusting for all variables (see Table 1 ). The dependent variable was the linear SDM composite score. In all analyses, we accounted for the complex design of the MEPS and present weighted percentages. ${ }^{11,12}$ We performed all analyses with SAS version 9.4 (SAS Institute, Inc). The Harvard Medical School Institutional Review Board determined that this study did not constitute human subjects research.

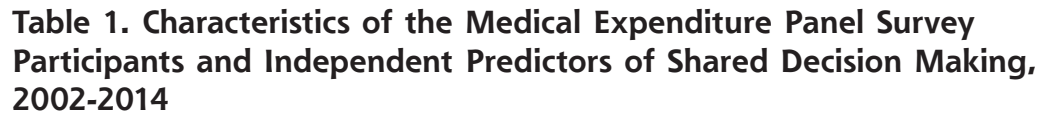

\begin{tabular}{|c|c|c|c|}
\hline \multirow[b]{2}{*}{ Characteristic } & \multicolumn{2}{|c|}{$\begin{array}{c}\text { Mean Value }(95 \% \mathrm{Cl}) \text { or } \\
\%(95 \% \mathrm{CI})^{\mathrm{a}}\end{array}$} & \multirow{2}{*}{$\begin{array}{l}\text { Association With } \\
\text { SDM Composite } \\
\text { Score, }{ }^{b} \text { Points }\end{array}$} \\
\hline & $\begin{array}{c}2002 \\
(n=12,138)\end{array}$ & $\begin{array}{c}2014 \\
(n=9,049)\end{array}$ & \\
\hline SDM composite score, points & $4.4(4.3-4.4)$ & $5.0(4.9-5.1)$ & $\mathrm{n} / \mathrm{a}$ \\
\hline Age, y & $49.3(48.8-49.8)$ & $51.8(51.1-52.5)$ & $0.01^{c}$ \\
\hline Female $^{d}$ & $59.6(58.8-60.4)$ & $59.1(58-60.1)$ & $0.06^{c}$ \\
\hline \multicolumn{4}{|l|}{ Race/ethnicity } \\
\hline Non-Hispanic white & $76.3(74.8-77.8)$ & $71.7(69.4-74.0)$ & Referent \\
\hline Hispanic & $8.5(7.5-9.5)$ & $10.8(9.3-12.3)$ & -0.03 \\
\hline Non-Hispanic black & $10.2(9.2-11.2)$ & $10.8(9.4-12.1)$ & $0.33^{c}$ \\
\hline Non-Hispanic Asian & $3.0(2.4-3.6)$ & $4.0(3.1-5.0)$ & $-0.29^{c}$ \\
\hline $\begin{array}{l}\text { Non-Hispanic other or } \\
\text { multiple }\end{array}$ & $2.0(1.5-2.5)$ & $2.7(2.0-3.4)$ & 0.08 \\
\hline \multicolumn{4}{|l|}{ Census region } \\
\hline Northeast & $21.3(19.6-23.1)$ & $18.3(16.5-20.0)$ & Referent \\
\hline Midwest & $24.1(22.1-26.0)$ & $23.0(21.2-24.8)$ & 0 \\
\hline South & $34.3(32.1-36.5)$ & $37.2(35.0-39.5)$ & -0.01 \\
\hline West & $20.3(18.5-22.0)$ & $21.5(19.8-23.1)$ & $-0.21^{c}$ \\
\hline \multicolumn{4}{|l|}{ Partner status } \\
\hline Married/partnered & $60.9(59.5-62.3)$ & $57.6(55.8-59.4)$ & Referent \\
\hline Widowed & $8.8(8.1-9.4)$ & $8.3(7.5-9.1)$ & $0.10^{c}$ \\
\hline Divorced/separated & $12.8(12.0-13.6)$ & $14.0(12.9-15.0)$ & $0.05^{c}$ \\
\hline Never married & $17.6(16.7-18.5)$ & $20.2(18.9-21.4)$ & -0.03 \\
\hline \multicolumn{4}{|l|}{ Education } \\
\hline$<$ High school & $19.4(18.3-20.4)$ & $11.2(10.3-12.1)$ & Referent \\
\hline $\begin{array}{l}\text { High school/GED/some } \\
\text { college }\end{array}$ & $54.1(52.9-55.2)$ & $57.5(55.9-59.2)$ & $-0.09 c$ \\
\hline Bachelor's degree & $15.8(14.9-16.8)$ & $18.8(17.6-20.0)$ & $-0.19 c$ \\
\hline >Bachelor's degree & $10.7(9.9-11.5)$ & $12.5(11.3-13.6)$ & $-0.26 c$ \\
\hline \multicolumn{4}{|l|}{ Health insurance coverage } \\
\hline Any private & $77.7(76.4-79.0)$ & $71.9(70.2-73.6)$ & Referent \\
\hline Public only & $16.2(15.1-17.3)$ & $23.6(22.1-25.1)$ & 0.04 \\
\hline Uninsured & $6.1(5.5-6.8)$ & $4.5(3.8-5.1)$ & -0.17 \\
\hline \multicolumn{4}{|l|}{ Perceived health status } \\
\hline Excellent & $21.2(20.2-22.3)$ & $21.2(19.9-22.5)$ & Referent \\
\hline Very good & $32.8(31.7-34.0)$ & $32.2(30.7-33.6)$ & $-0.32^{c}$ \\
\hline Good & $28.9(27.9-30.0)$ & $28.9(27.6-30.3)$ & $-0.41^{c}$ \\
\hline Fair & $11.9(11.2-12.7)$ & $13.3(12.3-14.2)$ & $-0.33^{c}$ \\
\hline Poor & $5.1(4.6-5.6)$ & $4.4(3.9-5.0)$ & $-0.15^{c}$ \\
\hline $\begin{array}{l}\text { Usual source of care is } \\
\text { same race/ethnicity }\end{array}$ & $41.1(39.2-43.0)$ & $36.3(34.0-38.6)$ & $0.24^{c}$ \\
\hline Employed $^{d}$ & $66.5(65.2-67.8)$ & $63.6(62.0-65.2)$ & $-0.09 c$ \\
\hline Currently smoked & $19.3(18.3-20.2)$ & $13.1(12.1-14.1)$ & 0.02 \\
\hline Need help with $A D L^{e}$ & $3.9(3.4-4.3)$ & $4.4(3.8-4.9)$ & $0.20^{c}$ \\
\hline Need help with iADL ${ }^{\mathrm{e}}$ & $7.0(6.4-7.7)$ & $7.5(6.8-8.3)$ & $0.13 c$ \\
\hline SF-12 PCS score s $^{f}$ & $47.0(46.7-47.3)$ & $47.1(46.7-47.5)$ & $0.03^{c}$ \\
\hline SF-12 MCS scoref & $50.3(50.1-50.6)$ & $51.1(50.8-51.4)$ & 0.04 \\
\hline Body mass index, $\mathrm{kg} / \mathrm{m}^{2}$ & $27.4(27.3-27.6)$ & $28.6(28.4-28.8)$ & $0.01^{c}$ \\
\hline
\end{tabular}

\section{RESULTS}

From 2002 to 2014, participants in MEPS became older, less white, more Hispanic, and more educated, 
Figure 1a. Trends in components of shared decision making, 2002-2014.

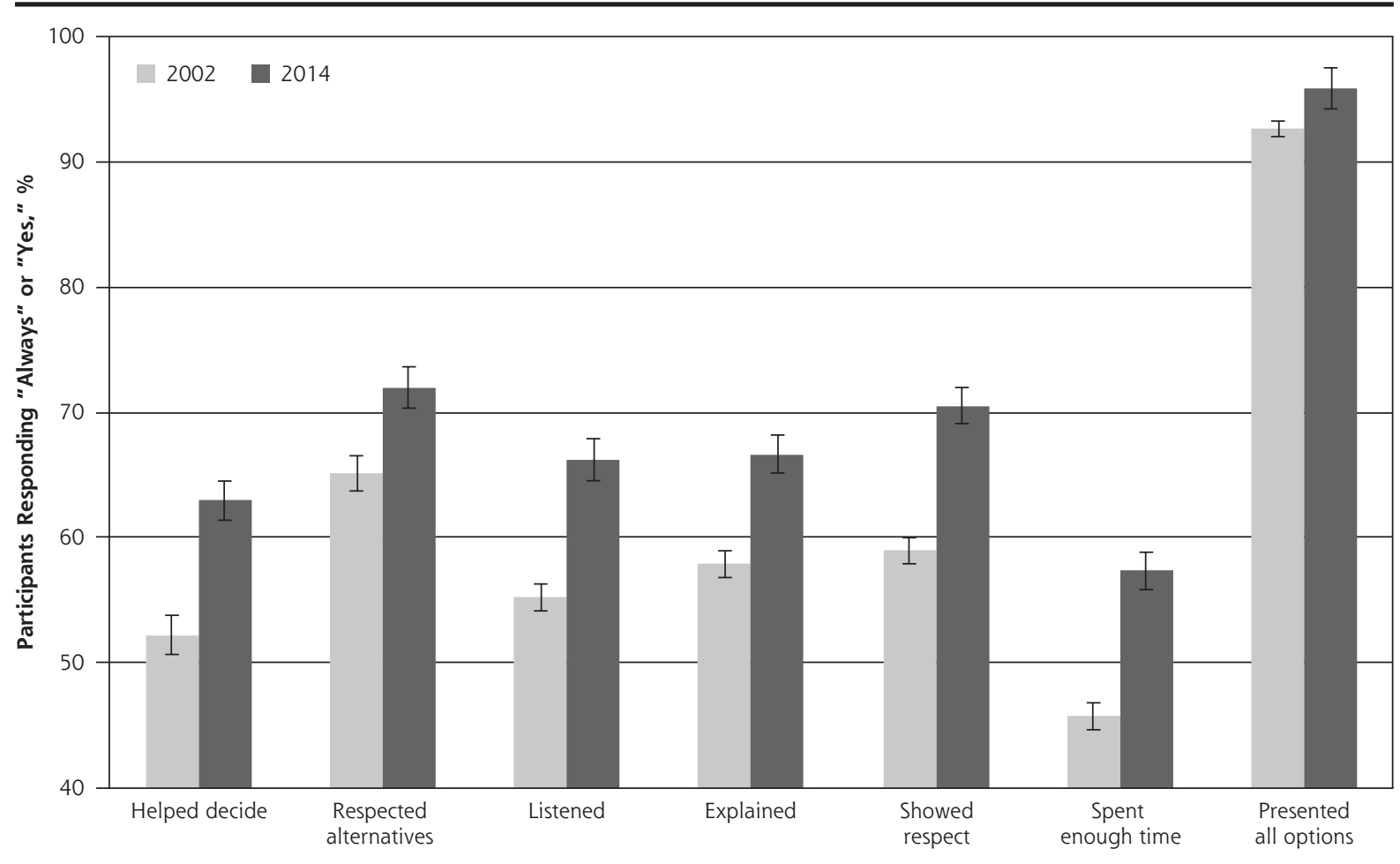

Note: Change between 2002 and 2014 for each question included in the SDM composite. All comparisons $P<.01$.

Error bars represent $95 \%$ Cls (for verbatim questions, see Supplemental Appendix, available at http://www.AnnFamMed.org/content/15/6/552/suppl/DC1/).

Figure 1b. Trend in shared decision-making composite score, 2002-2014.

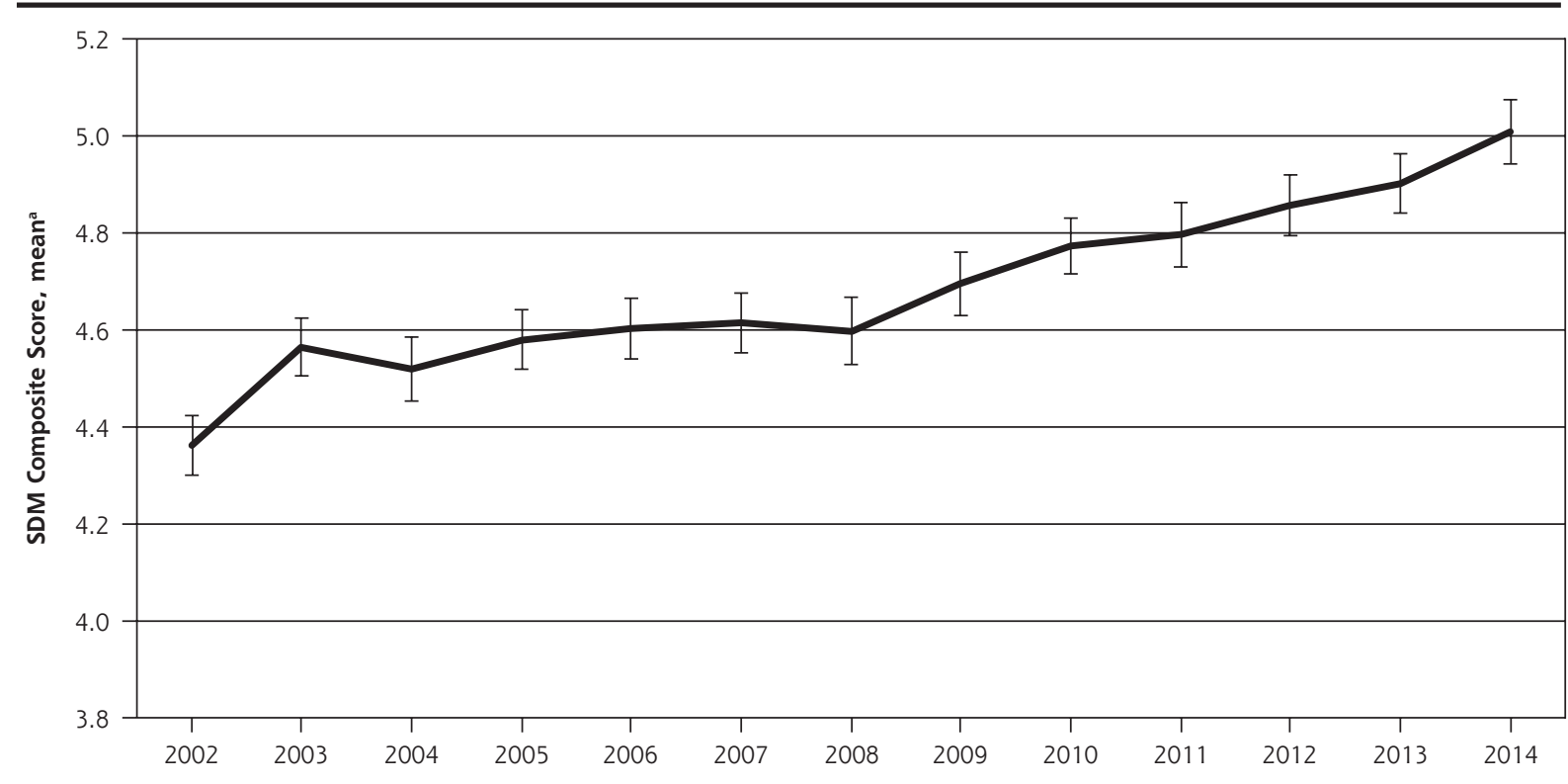

SDM $=$ shared decision making.

a Number of points out of 7 .

Note: Change from 2002 to 2014 in the SDM composite score. Comparison of 2002 to 2014: $P<.01$.

Error bars represent 95\% Cls (for verbatim questions, see Supplemental Appendix, available at http://www.AnnFamMed.org/content/15/6/552/suppl/DC1/). 
and better decisions regarding use of services with marginal, unclear, or no benefit, ${ }^{2,3}$ the impact of these improvements on overall outpatient quality of care is unclear. ${ }^{14}$ Second, additional items or direct observation (vs self-report), or both may better capture SDM. Others have found low rates of SDM (eg, 3 to 50 points out of 100 with a different instrument). ${ }^{15}$ Third, we could not assess SDM for specific clinical questions (eg, mammography before age 50) that might vary based on patient preferences. Fourth, we were unable to capture some factors that might influence SDM, such as time pressure or inadequate reimbursement. Fifth, unmeasured confounding precludes a definitive answer as to whether the observed independent predictors of SDM in fact play a causal role. Finally, not all patients desire SDM, so the ideal level of this form of decision making is unknown. ${ }^{13}$

Among adult Americans, patient-reported use of SDM increased significantly from 2002 to 2014 , despite sociodemographic disparities and poor performance in some areas. Beyond increasing insurance coverage, efforts to improve SDM should target Americans without a same-race/ethnicity usual source of care and with poor perceived health.

To read or post commentaries in response to this article, see it online at http://www.AnnFamMed.org/content/15/6/552.

Key words: shared decision making; patient-centered care; clinical decision-making; decision support techniques; primary care

Submitted January 27, 2017; submitted, revised, June 14, 2017; accepted July 7, 2017.

Funding support: Dr Levine received funding support from an Institutional National Research Service Award (T32HP10251), the Ryoichi Sasakawa Fellowship Fund, and the Brigham and Women's Hospital Division of General Internal Medicine and Primary Care.

Disclaimer: All funding sources had no role in the design and conduct of the study; collection, management, analysis, and interpretation of the data; preparation, review, or approval of the manuscript; and decision to submit the manuscript for publication.

Previous presentation: Presented at the Society of General Internal Medicine - New England Regional Meeting; March 9, 2017; Boston, Massachusetts.

Author contributions: D.M.L. had full access to all of the data in the study and takes responsibility for the integrity of the data and the accuracy of the data analysis; Study concept and design: D.M.L.; Acquisition, analysis, or interpretation of data: all authors; Drafting of the manuscript: D.M.L.; Critical revision of the manuscript for important intellectual content: all authors; Statistical analysis: D.M.L.; Administrative, technical, or material support: D.M.L.; Study supervision: B.E.L. and J.A.L.
Supplementary materials: Available at http://www.AnnFamMed. org/content/15/6/552/suppl/DC1/.

\section{References}

1. Charles C, Gafni A, Whelan T. Shared decision-making in the medical encounter: what does it mean? (or it takes at least two to tango). Soc Sci Med. 1997;44(5):681-692.

2. Austin CA, Mohottige D, Sudore RL, Smith AK, Hanson LC. Tools to promote shared decision making in serious illness: a systematic review. JAMA Intern Med. 2015;175(7):1213-1221.

3. Hess EP, Hollander JE, Schaffer JT, et al. Shared decision making in patients with low risk chest pain: prospective randomized pragmatic trial. BMJ. 2016;355(December):i6165.

4. Stiggelbout AM, Van der Weijden T, De Wit MP, et al. Shared decision making: really putting patients at the centre of healthcare. BMJ. 2012;344:e256.

5. Kon AA. The shared decision-making continuum. JAMA. 2010; 304(8):903-904.

6. Conway P, Bindman AB. Improving the Quality of Care for Medicare Beneficiaries by Increasing Patient Engagement. The CMS Blog. Patient-Centered Primary Care Collaborative. https://www.pcpcc. org/2016/12/09/improving-quality-care-medicare-beneficiariesincreasing-patient-engagement. Published Dec 8, 2016. Accessed Dec 13, 2016.

7. RTI International. MEPS Medical Provider Component: Annual Contractor Methodology Report 2015 Data Collection. Rockville, MD; 2017. https://meps.ahrq.gov/data_files/publications/annual_contractor_ report/mpc_ann_cntrct_methrpt.pdf. Published Jun 2017. Accessed Mar 18, 2016.

8. Fiks AG, Mayne S, Localio AR, Alessandrini EA, Guevara JP. Shared decision-making and health care expenditures among children with special health care needs. Pediatrics. 2012;129(1):99-107.

9. Fiks AG, Localio AR, Alessandrini EA, Asch DA, Guevara JP. Shared decision-making in pediatrics: a national perspective. Pediatrics. 2010;126(2):306-314.

10. Lipsitz SR, Fitzmaurice GM, Sinha D, Hevelone N, Giovannucci E, $\mathrm{Hu}$ JC. Testing for independence in J $\times \mathrm{K}$ contingency tables with complex sample survey data. Biometrics. 2015;71(3):832-840.

11. Machlin S, Yu W, Zodet M. Medical Expenditure Panel Survey Computing Standard Errors for MEPS Estimates. Rockville, MD; 2005. http: I/meps.ahrq.gov/mepsweb/survey_comp/standard_errors.jsp. Published Jan 2005. Accessed Jan 22, 2016.

12. Cohen $S$, Machlin S. Nonresponse adjustment strategy in the household component of the 1996 Medical Expenditure Panel Survey. J Econ Soc Meas. 1998;25(1):15-33.

13. Levinson W, Kao A, Kuby A, Thisted RA. Not all patients want to participate in decision making. A national study of public preferences. J Gen Intern Med. 2005;20(6):531-535.

14. Levine DM, Linder JA, Landon BE. The quality of outpatient care delivered to adults in the United States, 2002 to 2013. JAMA Intern Med. 2016;176(12):1778-1790.

15. Couët N, Desroches S, Robitaille H, et al. Assessments of the extent to which health-care providers involve patients in decision making: a systematic review of studies using the OPTION instrument. Health Expect. 2015;18(4):542-561. 